\title{
Age-related differences in the preweanling rat's reactivity to footshock
}

\author{
JAMES R. MISANIN \\ Susquehanna University, Selinsgrove, Pennsylvania \\ and \\ CHARLES F. HINDERLITER \\ University of Pittsburgh, Johnstown, Pennsylvania
}

\begin{abstract}
Unconditioned reactivity to footshock in 5-, 7-, 9-, 11-, and 13-day-old rats was assessed by measuring locomotor activity elicited by inescapable shock. Five-day-old rats differed in activity from all ages except the 7-day-olds. The 7-day-olds were less active than the 13-day-olds, and the 9-13-day-olds failed to differ from one another. These findings suggest that an age difference in reactivity to footshock was probably not a determining factor in reported age-related differences in the shock-escape behavior of infant rats.
\end{abstract}

Electric shock is used extensively as a negative reinforcer to examine learning in animals in a laboratory setting. Its termination or prevention is generally effective in increasing those behaviors most directly associated with stimulus offset. A factor found to increase the effectiveness of the stimulation is the organism's unconditioned reaction to the aversive stimulus. Boice, Boice, and Dunham (1968), for example, reported that laboratory mice, which are more reactive to footshock than are gerbils or kangaroo rats, had lower escape latencies and made more avoidances than either of the other two species. Collier and Bolles (1980) further demonstrated that defensive reactions to footshock change with age during the preweaning period. Thus, when shock is used to examine the capability of the developing organism to acquire and retain various instrumental responses, it is important to know whether developmental changes in performance reflect changes in learning capability or changes in the animals' unconditioned reactions to the aversive stimulus. Misanin, Haigh, Hinderliter, and Nagy (1973), for example, found age differences in the shock-escape behavior of 5-11-day-old rats and attributed these differences to ontogenetic changes in the rat's learning capability, whereas others maintained that such performance differences reflected age-dependent changes in reactivity to shock (Campbell \& Coulter, 1976).

Although Campbell (1967) has demonstrated that animals 20 days of age and older are equally reactive to low and moderate levels of footshock, relatively little is known about the rat's unconditioned reaction to footshock during the preweaning period. The purpose of

James R. Misanin's mailing address is: Department of Psychology, Susquehanna University, Selinsgrove, Pennsylvania 17870. Charles F. Hinderliter's mailing address is: Department of Psychology, University of Pittsburgh, Johnstown, Pennsylvania 15904. the present experiment was, therefore, to examine the 5-13-day-old rat's unconditioned reactivity to shock as measured by the activity elicited by inescapable shock.

To increase the generality of our findings, four different strains and five different ages of rats were tested at each of three shock levels.

\section{METHOD}

\section{Subjects}

Nine rats at each of five age levels $(5,7,9,11$, and 13 days) comprised the forty-five rats of each of four strains that were used in this experiment. The strains were: Long-Evans black, Long-Evans hooded, Sprague-Dawley albino, and Wistar albino. All animals were born in the university animal colony and were kept on pine shavings in $46 \times 23 \times 13 \mathrm{~cm}$ polyethylene cages with their mothers; the mothers had ad-lib access to food and water. The animal colony was maintained on a 14-h-light/ 10-h-dark cycle.

\section{Apparatus}

The apparatus was a 12-cm-long, 6-cm-wide, and 7-cm-high clear-acrylic enclosure mounted $4 \mathrm{~mm}$ above a grid floor. The floor was made of 1-mm-diam stainless steel rods mounted in acrylic at 4-mm intervals. The rods ran parallel to the length of the rectangular enclosure. The grid floor had a central axle that was mounted in ball bearings to reduce friction. To reduce tension on the floor that would be produced by conventional grid wiring, shock was delivered from a Harvard Instrument shock generator and scrambler (Model HI 3121) through mercury wells, the mercury in each well making continuous contact with a $5-\mathrm{mm}$ length of platinum wire connected to a different one of the rods in the grid floor. This ball-bearing and wiring arrangement was sufficient to cause a 1-g weight placed $1 \mathrm{~cm}$ on either side of the central axle to tilt the grid floor $2 \mathrm{~mm}$, thus making or breaking the contact of a mercury switch that was connected to a counter to count crossings. The apparatus was housed in a $44 \times 40 \times 32 \mathrm{~cm}, .5$-in. plywood chamber.

\section{Procedure}

Three rats of each age from each strain were tested on each of three shock levels $(.04, .10$, and $.16 \mathrm{~mA})$ that were chosen 
to bracket the $.10-\mathrm{mA}$ shock level that generally has been used in escape (Misanin et al., 1973; Misanin, Nagy, \& Weiss, 1970) and avoidance (Spear \& Smith, 1978) training of infant rats. Testing consisted of removing the rat from its home cage, placing it across the central axle of the grid floor, and subjecting it to inescapable shock for $10 \mathrm{~min}$. Each animal was subjected to a single level of shock, and the number of times it crossed the central axle of the grid floor (cage crossing) during each 2-min period of the 10 -min session was recorded automatically.

\section{RESULTS}

The number of cage crossings per 2-min period at each shock level was averaged for each age and strain and analyzed as a split-plot factorial design (SPF-345.5; Kirk, 1982), with shock level, strain, age, and period being the factors under consideration. With the significance level set at .05 , this analysis yielded significant main effects of age $[F(4,120)=12.12]$ and period $[F(4,480)=35.49]$. There were no main or interaction effects involving strain or shock level (all Fs $\leqslant 1.66$ ). Apparently, a wide range of low-level shocks are equally motivating at these age levels for a variety of rat strains.

A comparison between ages indicated that, overall, the 5-day-olds failed to differ from the 7-day-olds $[F(1,120)=1.47]$ but did differ significantly from all other age groups $[\mathrm{Fs}(1,120) \geqslant 6.65]$. The 7-day-old rats did not differ from the 9-or 11-day-olds $[\mathrm{Fs}(1,120)$ $\leqslant 2.18$ ] but did differ significantly from the 13-day-old rats $[F(1,120)=5.84]$. The 9-, 11-, and 13-day-olds did not differ significantly from one another $[\mathrm{Fs}(1,120)$ $\leqslant 1.10]$.

In general, the number of cage crossings decreased over the 10-min session; however, there was a significant Age by Period interaction $[F(16,480)=4.92]$. This interaction is depicted in Figure 1. The number of cage crossings remained relatively constant from period to period for the 5 - and 7-day-olds $[\mathrm{Fs}(1,600) \leqslant 3.30]$ but decreased significantly for the 9-13-day-olds $[\mathrm{Fs}(1,600)$ $\geqslant 6.27]$.

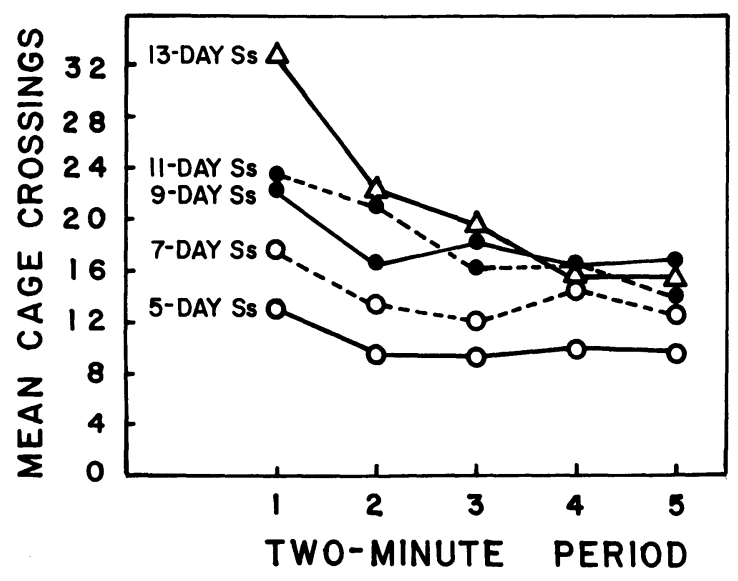

Figure 1. Mean cage crossings per 2-min period as a function of age.

\section{DISCUSSION}

The present results suggest that reactivity to footshock is not a significant factor influencing reported age differences in shockescape or avoidance performance in rats ranging in age from 9 to 13 days. However, locomotor responses to shock do vary with age when younger (5-7-day-old) age groups are included, and this is a factor to be considered when making between-age comparisons of performance on shock-motivated tasks. For example, Misanin, Nagy, Keiser, and Bowen (1971), who used .10 mA as a motivating stimulus, reported age differences in speed of escape in 5-, 7-, 9-, and 11-day-old rats. Although it is possible, indeed, is highly probable, that a difference in speed of the 5- and 9-day-olds or of the 7- and 11-day-olds may, in part, reflect age-related differences in reactivity to shock or in locomotor capability, it is unlikely that the reported performance difference of adjacent age groups, that is, 5 and 7 days, 7 and 9 days, and 9 and 11 days (Misanin et al., 1971), can be attributed to age differences in reactivity to footshock, since the present results indicate that adjacent age groups differ little, if at all, in activity elicited by shock.

When young rats are subjected to a noxious stimulus, they exhibit a pivoting or turning reaction (Gard, Hård, Larsson, \& Petersson, 1967), which tends to decrease with repeated stimulation if the noxious stimulus is escapable (Misanin et al., 1970). Age differences in the rate of decreasing such reactions in the shock-escape situation have been attributed to developmental changes in learning capability (Misanin et al., 1971) and to ontogenetic changes in reactivity to shock (Campbell \& Coulter, 1976). The results of the present study have a bearing on these interpretations. Significant correlations between speed of escape and turns per trial of $-.96,-.93,-.94$, and -.98 have been reported for 5-, 7-, 9-, and 11-day-old rats, respectively, in a shock-escape situation (Misanin et al., 1973). Thus, the fewer such turns an infant rat makes, the more quickly reinforcement, that is, shock offset, occurs. In the straight-alley shock-escape situation, 5-, 7-, 9-, and 11-day-old rats significantly decrease turning and other superfluous activity over the training session (Misanin et al., 1973). It is unlikely that this decrease in turning of 5- and 7-day-old rats is due to an intrasession change in sensitivity (habituation) to shock since, in the present study, in which a decrease in activity was not reinforced, 5- and 7-day-olds showed no tendency to decrease activity over an extended shock session. An intrasession change in reactivity to shock may, however, play a role in the decrease in turning observed in 9-13-day-old rats since, in the present study, these age groups did significantly decrease motor activity over the 10-min shock session. It is unlikely, however, that age differences in reactivity to footshock can account for the reported age differences in rate of decreasing turning of 9-13-day-old rats in the shock-escape situation (Misanin et al., 1970, 1971, 1973). In the shockescape situation, activity elicited by shock is inversely related to age, whereas, in the present study, it was not.

Although the present results do not suggest that age differences in performance in a shock-escape situation reflect developmental differences in learning capability, they do suggest that an age difference in reactivity to shock is probably not the determining factor in age-related differences in shock-escape and avoidance behavior of infant rats.

\section{REFERENCES}

Boice, R., Boice, C., \& Dunham, A. E. Role of docility in avoidance: Gerbils and kangaroo rats in a shuttlebox. Psychonomic Science, 1968, 10, 381-382.

Campbell, B. A., \& Coulter, X. Ontogeny of learning and memory. In M. R. Rosenzweig \& E. L. Bennet (Eds.), Neural mechanisms of learning and memory. Cambridge, Mass: MIT Press, 1976.

Campbell, B. A. Developmental studies of learning and motivation in infraprimate mammals. In H. W. Stevenson, E. H. Hess, 
\& H. L. Rheingold (Eds.), Early behavior: Comparative and developmental approaches. New York: Wiley, 1967.

Collier, A. C., \& Bolles, R. C. The ontogenesis of defensive reactions to shock in preweanling rats. Developmental Psychobiology, 1980, 13, 141-150.

Gard, C., HÅrd, R., Larsson, K., \& Petersson, V. The relationship between sensory stimulation and gross motor behavior during the postnatal development in the rat. Animal behaviour, 1967, 15, 563-567.

KIRK, R. E. Experimental design: Procedures for the behavioral sciences. Monterey, California: Brooks/Cole, 1982.

Misanin, J. R., Haigh, J. M., Hinderliter, C. F., \&
NAGY, Z. M. Analysis of response competition in discriminated and nondiscriminated escape training of neonatal rats. Journal of Comparative and Physiological Psychology, 1973, 85, 570-580.

Misanin, J. R., Nagy, Z. M., Keiser, E. G., \& Bowen, W. Emergence of long-term memory in the neonatal rat. Journal of Comparative and Physiological Psychology, 1971, 77, 188-199.

Misanin, J. R., NAGY, Z. M., \& Weiss, E. M. Escape behavior in neonatal rats. Psychonomic Science, 1970, 18, 191-192.

SpeAr, N. E., \& Smith, G. J. Alleviation of forgetting in preweanling rats. Developmental Psychobiology, 1978, 11, 513-529.

(Received for publication March 14, 1983.) 